\title{
Pengukuran Laju Temperatur Pemanas Listrik Berbasis Lm-35 Dan Sistem Akuisisi Data Adc-0804
}

\author{
Ummu Kalsum \\ Universitas Sulawesi Barat \\ e-mail: Ummu.kalsum@unsulbar.ac.id
}

\begin{abstract}
Abstrak
Penelitian ini merupakan pengukuran laju temperatur pemanas listrik dengan menggunakan LM35 dan sistem akuisisi data ADC-0804. Keluaran dari sensor suhu LM 35 dikuatkan dengan penguat non-inverting. Besar penguatan yang diberikan sebesar 5 kali penguatan. Jenis op-amp yang digunakan adalah LM-324. Untuk menghubungkan ADC dan LPT digunakan multiplekser tipe 74LS157. Selanjutnya, data yang direkam pada PC diolah dengan menggunakan program "Delphi 7". Hasil pengukuran laju suhu menggunakan sistem akusisi berbasis ADC-0804 dari alat pemanas adalah 0,390625 ${ }^{\circ} \mathrm{C} / \mathrm{s}$. Hasil ini menunjukkan bahwa sensor suhu berbasis LM-35 sangat sesuai digunakan untuk rentang pengukuran suhu yang rendah.
\end{abstract}

Kata kunci: sensor LM35,penguat non-inverting, ADC0804,laju suhu

\section{PENDAHULUAN}

Sensor merupakan peralatan yang berfungsi untuk mendeteksi gejala atau signal yang berasal dari perubahan suatu besaran tertentu menjadi besaran listrik.[Fraden, 2003] Contohnya, besaran suhu menjadi tegangan listrik. Salah satu komponen elektronika yang dapat digunakan sebagai sensor suhu adalah LM35. LM35 menunjukkan adanya linearitas antara suhu tegangan keluaran yang dihasilkan[Nurhayati, 2012].

Selain itu, LM35 mempunyai keluaran impedansi yang rendah dan linieritas yang tinggi sehingga mudah dihubungkan dengan rangkaian kendali khusus serta tidak memerlukan pengolahan tegangan analog lanjutan. LM35 hanya membutuhkan arus sebesar $60 \mu \mathrm{A}$ hal ini berarti LM35 mempunyai kemampuan menghasilkan panas (SELF-HEATING) dari sensor yang dapat menyebabkan kesalahan pembacaan yang rendah yaitu kurang dari $0,5^{\circ} \mathrm{C}$ pada suhu $25^{\circ} \mathrm{C}$ [Candra, 2014] 


\section{JURNAL SAINTIFIK VOL.2 NO.2, JULI 2016}
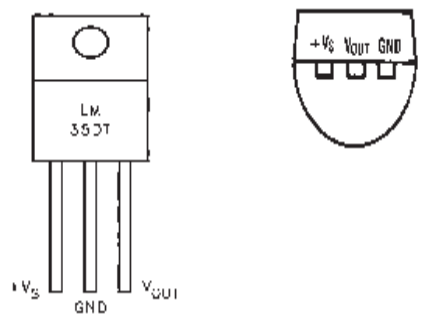

Gambar 1.Sensor Suhu LM35

Gambar 1 menunjukan bentuk dari LM35 tampak depan dan tampak bawah. 3 pin LM35 menujukan fungsi masing-masing pin diantaranya, pin 1 berfungsi sebagai sumber tegangan kerja dari LM35, pin 2 atau tengah digunakan sebagai tegangan keluaran atau $\mathrm{V}_{\text {out }}$ dengan jangkauan kerja dari 0 Volt sampai dengan 1,5 Volt dengan tegangan operasi sensor LM35 yang dapat digunakan antar 4 Volt sampai 30 Volt.[Shatomedia, 2014]

Secara prinsip, sensor LM35 akan melakukan penginderaan pada saat terjadi perubahan suhu setiap suhu $1{ }^{\circ} \mathrm{C}$ dengan penunjukan tegangan sebesar $10 \mathrm{mV}$. Hal ini berarti keluaran sensor ini akan naik sebesar $10 \mathrm{mV}$ setiap derajat Celcius sehingga diperoleh persamaan sebagai berikut :

$$
\mathbf{V}_{\text {LM35 }}=\text { Suhu }^{*} 10 \mathrm{mV}
$$

Adapun karakteristik dari IC LM 35 adalah :

- Kalibrasi dalam satuan derajat celcius.

- Lineritas $+10 \mathrm{mV} /{ }^{\circ} \mathrm{C}$.

- Akurasi $0,5^{\circ} \mathrm{C}$ pada suhu ruang.

- Range $-55^{\circ} \mathrm{C}-150^{\circ} \mathrm{C}$.

- Dioperasikan pada catu daya $4 \mathrm{~V}-30 \mathrm{~V}$.

- Arus yang mengalir kurang dari $60 \mu \mathrm{A}$

- Impedansi keluaran yang rendah $0,1 \Omega$ untuk $1 \mathrm{~mA}$ [datasheet, 2014]

Pada rancang bangun sistem akusisi data digunakan tegangan kerja sebesar 5 volt. Sensor LM35 nantinya akan dihubungkan dengan rangkaian penguat non-inverting. Noninverting amplifier adalah suatu operasional amplfier yang dirancang untuk memberikan penguatan tegangan yang positif [Sadiku, 2009].

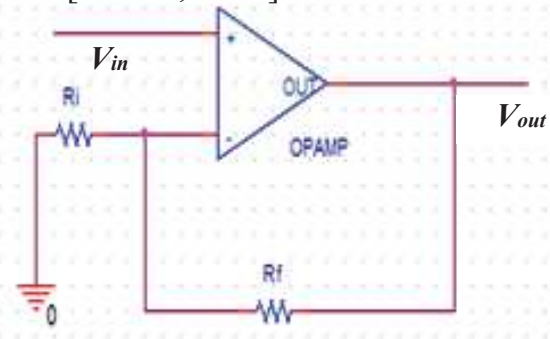

Gambar 2. Rangkaian non-inverting 
Arus $\boldsymbol{i}$ mengalir ke $\boldsymbol{R} \boldsymbol{i}$ karena impedansi masukan op-amp sangat besar sehingga tidak ada arus yang mengalir pada kedua terminal masukannya. Tegangan pada $\boldsymbol{R} \boldsymbol{i}$ sama dengan perbedaan tegangan pada kedua terminal masukannya, mendekati 0 Volt.

$$
i=\frac{V_{i}}{R_{i}}
$$

Sedangkan tegangan pada $\boldsymbol{R} \boldsymbol{f}$ :

$$
V_{R_{f}}=i \cdot \mathrm{R}_{f}=\frac{R_{f}}{R_{i}} V_{i}
$$

Tegangan keluaran Vo di dapat dengan menambahkan tegangan pada Ri yaitu Vi dengan tegangan pada Rf.

$$
\begin{aligned}
& V_{0}=V_{i}+\frac{R_{f}}{R_{i}} V_{i} \\
& \frac{V_{0}}{V_{i}}=1+\frac{R_{f}}{R_{i}} \\
& A_{v}=\left(1+\frac{R_{f}}{R_{i}}\right)
\end{aligned}
$$

Dengan $A_{v}$ adalah besar Penguatan pada Op-amp non-inverting.[Santoso, 2013]

Untuk proses pengkonversian data dari analog ke digital digunakan ADC-0804. ADC (Analog to Digital Converter) merupakan suatu interface yang dapat mengubah tegangan analog menjadi digital. Interface ini dibutuhkan karena komputer hanya dapat mengolah sinyal digital sehingga keberadaan ADC sangat diperlukan pada sistem pengukuran laju suhu. Batasan tegangan yang dapat diubah oleh $\mathrm{ADC}$ sesuai dengan lebar data dan tegangan referensi yang diberikan. Tegangan referensi menentukan minimal dan maksimal tegangan masukan yang dapat diterima oleh ADC

sedangkan lebar data (dalam format biner) menentukan step cacahan yang akan membagi tegangan referensi tersebut. Dengan demikian, untuk mengetahui besarnya tegangan tiap bitnya yaitu tegangan referensi dibagi dengan jumlah step/cacahan yang ada.[Handoyo, 2008]

ADC-0804 mempunyai lebar data 8 bit (bit 0 - bit 7) dengan besar tegangan referensi 5 volt. Hal ini berarti resolusi pembacaan ADC-0804 sebesar :

$$
=\frac{5 \text { volt }}{2^{8} \text { bit }}=\frac{5 \text { volt }}{255}=0,019 \text { volt } / \mathrm{bit} \text {. }
$$

Jika data yang ditunjukkan sensor lebih kecil dari 0,019 V/bit (misal 0,015 V/bit) maka data tersebut tidak dapat dibaca oleh ADC.

Dari konfigurasi pin ADC 0804 terdapat 20 pin dengan fungsi :

- 'Pin 11 - pin 18 = keluaran data digital hasil konversi dari A/D. Kedelapan keluaran ini dapat langsung dihubungkan ke bus data.

- Pin 1, 2, dan 3 = pengondisi IC sebagai konversi signal analog atau tidak. Apabila pin 1 (CS) atau pin 2 (RD) diberi masukan tinggi (high) atau berlogika 1 maka keluaran pada pin 11 hingga pin 18 akan mengambang (high impedansi). Sebaliknya jika diberi masukan rendah atau berlogika 0 , maka A/D akan mengeluarkan data digital. Sedangkan pin 3 (WR) 
JURNAL SAINTIFIK VOL.2 NO.2, JULI 2016

merupakan pin yang berfungsi untuk memulai konversi sinyal analog menjadi signal digital. Jika kondisi (CS) dan (WR) rendah, maka konvekter akan mengalami reset dan apabila (WR) dalam keadaan tinggi maka konversi analog ke digital segera dimulai.

- A/D juga memerlukan detak atau clock untuk mengkonversi signal analaog menjadi data digital sebanyak 8 bit. Konversi detak harus terletak dalam daerah frekuensi 100 samapi 800 $\mathrm{kHz}$ pada pin 4 (CLK IN). Pada A/D ini sudah terdapat pembangkit clock internal dengan memasangkan rangkaian RC antara pin 4 (CLK IN) dan pin 19 (CLK R).

- $\quad$ Pin 5 = saluran yang digunakan untuk INTR, sinyal selesai konversi. ITR akan menjadi tinggi pada saat memulai konversi dan akan aktif rendah bila konversi telah selesai .

- Pin $20=$ pemberian tegangan atau catu daya ke rangkaian $\mathrm{A} / \mathrm{D}$, dimana tegangan kerja yang dibutuhkan sebesar $+5 \mathrm{~V}$ DC .

ADC 0804 mempunyai lebar data 8 bit, sehingga format data maksimalnya adalah 255 atau FFh. ADC 0804 mempunyai tegangan referensi pada pin 9, tegangan tersebut sebagai acuan dalam konversi bit/Volt.

Untuk mengangtifkan sistem ADC-0804, terdapat dua metode yang digunakan yaitu mode free running dan mode kontrol. Mode Free Running adalah kondisi dimana ADC akan mengeluarkan data hasil pembacaan input secara otomatis dan berkelanjutan setelah selesai mengkonversi analog ke digital. Pin INTR akan berlogika rendah setelah ADC selesai mengkonversi logika ini dihubungkan kepada masukan WR untuk memerintahkan ADC memulai konversi kembali. Sedangkan, mode kontrol merupakan kondisi dimana ADC baru memulai konversi setelah diberi instruksi. Hal ini dilakukan dengan memberikan pulsa rendah kepada WR sesaat $+1 \mathrm{~ms}$, kemudian membaca keluaran data ADC setelah keluaran INTR berlogika rendah.[Jefri, 2007]

\section{METODE PENELITIAN}

suhu yang dimaksud dalam perancangan ini adalah laju suhu. Untuk mengukur suhu alat pemanas listrik, sensor LM35 ditempelkan pada permukaan alat pemanas dengan cara menekan dengan kaca agar posisi sensor LM35 tepat menyentuh permukaan. Dalam mendeteksi suhu dengan menggunakan LM35 dapat dikalibrasikan langsung dalam ${ }^{\circ} \mathrm{C}$ (celcius).

Keluaran dari sensor dikuatkan dengan menggunakan rangkaian penguat non-inverting. Jenis op-amp yang digunakan dalam perancangan ini adalah LM-324. Salah satu karakteristik dari op-amp ini adalah dapat beroperasi dengan menggunakan single supply. Dalam perancangan ini, besar penguatan op-amp non-inverting yang digunakan yaitu :

$$
\begin{aligned}
A_{v} & =\frac{R_{f}}{R_{i}}+1 \\
& =\frac{10}{2,5}+1 \\
& =5 \text { kali }
\end{aligned}
$$

Untuk menghubungkan ADC dan LPT digunakan multiplekser tipe 74LS157. Selanjutnya, data yang direkam pada PC diolah dengan menggunakan program "Delphi7". Adapun gambar pada saat melakukan pengambilan data : 


\section{JURNAL SAINTIFIK VOL.2 NO.2, JULI 2016}

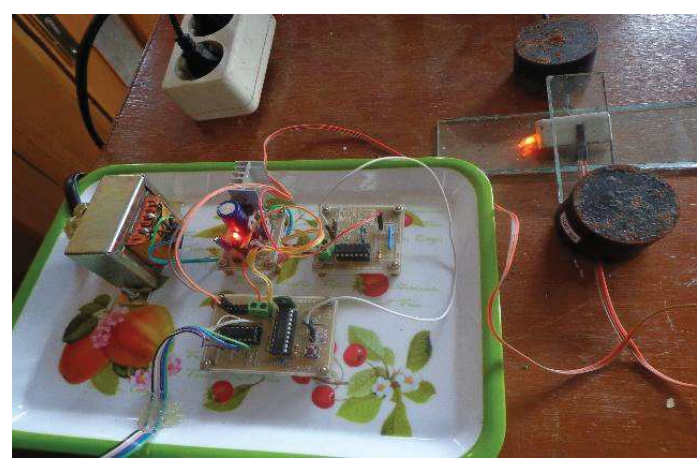

Gambar 3. Rangkaian pengukuran laju suhu

\section{HASIL DAN PEMBAHASAN}

Tabel 1 Hasil data yang direkam oleh PC.

\begin{tabular}{ccc}
\hline $\begin{array}{c}\text { Waktu } \\
(\mathrm{s})\end{array}$ & Suhu $\left({ }^{\circ} \mathrm{C}\right)$ & Laju Suhu $\left({ }^{\circ} \mathrm{C} / \mathrm{s}\right)$ \\
\hline 0 & 31,6 & - \\
1 & 31,6 & 0 \\
2 & 32 & 0,390625 \\
3 & 32,4 & 0,390625 \\
4 & 32,4 & 0 \\
5 & 32,8 & 0,390625 \\
6 & 33,2 & 0,390625 \\
7 & 33,2 & 0 \\
8 & 33,6 & 0,390625 \\
9 & 34 & 0,390625 \\
10 & 34,4 & 0,390625 \\
11 & 34,4 & 0 \\
12 & 34,8 & 0,390625 \\
13 & 35,2 & 0,390625 \\
14 & 35,2 & 0 \\
15 & 35,5 & 0,390625 \\
16 & 35,9 & 0,390625 \\
17 & 35,9 & 0 \\
18 & 36,3 & 0,390625 \\
19 & 36,7 & 0,390625 \\
20 & 37,1 & 0,390625 \\
\hline & &
\end{tabular}




\section{JURNAL SAINTIFIK VOL.2 NO.2, JULI 2016}

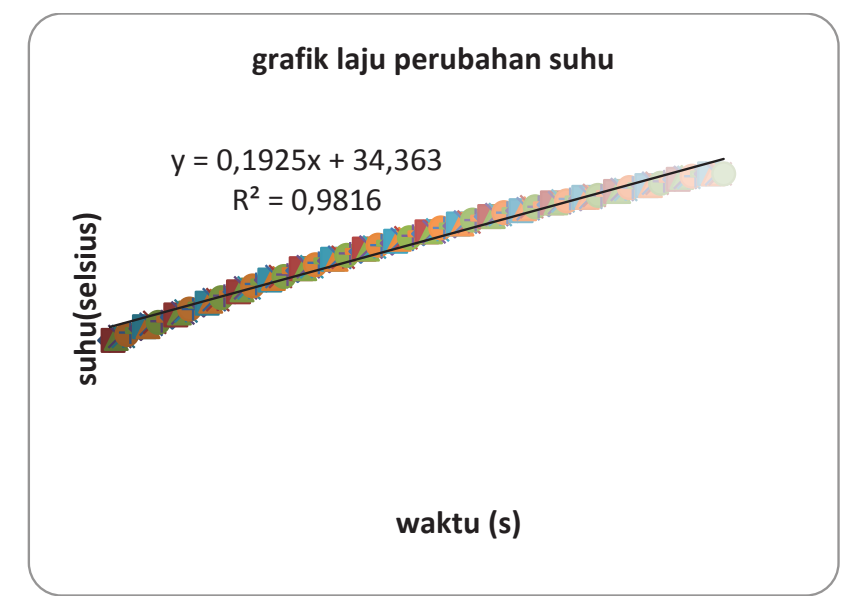

Gambar 4. hubungan antara suhu terhadap waktu pengukuran

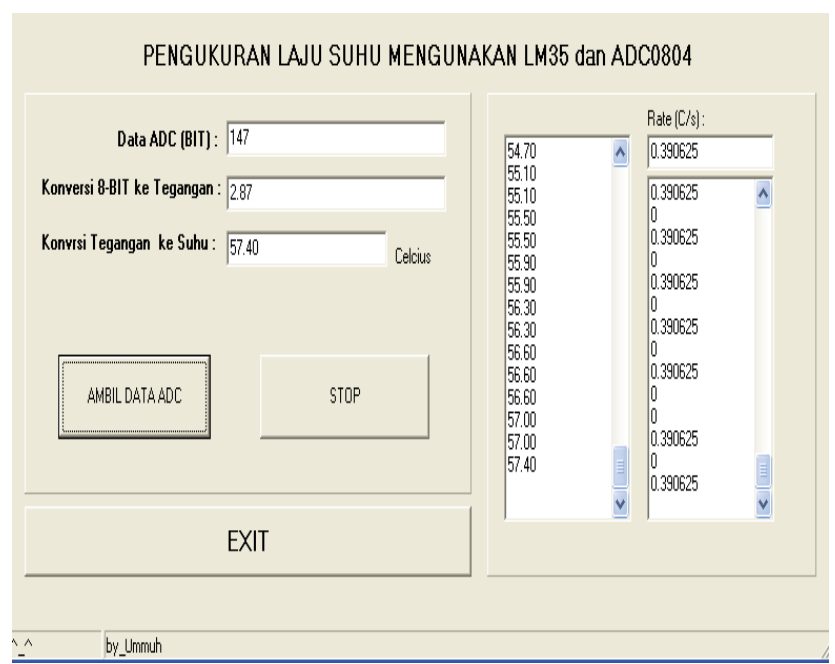

Gambar 5. Hasil penunjukkan data dengan menggunakan program delphi 7

Berdasarkan hasil data yang direkam oleh PC pada tabel 3.1 menunjukkan bahwa pada waktu ke-0 belum diperoleh data pengukuran laju suhu. Hal ini disebabkan karena laju suhu diperoleh dengan membandingkan suhu awal dengan suhu alat pemanas listrik pada waktu pengukuran berikutnya. Dalam hal ini tinjaun suhu dan waktu adalah selisih data awal dengan data berikutnya. Angka 0 pada tabel menunjukkan tidak terjadi perubahan suhu dan besar laju suhu konstan diperoleh sebesar $0,390625^{\circ} \mathrm{C} / \mathrm{s}$. Hal yang sama ditunjukkan pada grafik laju perubahan suhu yang memberikan hubungan yang linear. Hubungan ini bersesuain dengan karakteristik sensor LM35 yang bersifat linear.

Dalam rancangan ini digunakan penguat operasional untuk menyamakan resolusi dari ADC dengan output dari sensor. Resolusi dari ADC ( 8 bit) dengan tegangan 
referensi 5 Volt adalah sekitar $0,020 \mathrm{mV} /$ bit. Hal ini berarti bahwa setiap perubahan 1-bit menunjukan kenaikan tegangan $20 \mathrm{mV}$. Dapat dianalogikan jika ADC0804 mengeluarkan data 220-bit ( 11011100b) maka memiliki data tersebut akan terbagi menjadi dua bagian, yaitu 1101 dan 1100. Data akan masuk pada LPT secara bergantian dari bit terkecil (LSB) hingga terbesar (MSB).

\section{KESIMPULAN}

Sistem akuisisi data menggunakan ADC0804 untuk pengukuran laju temperatur pemanas listrik terdiri dari sistem sensor LM35, sistem penguat operasional LM324 dan A/D tipe ADC0804. Nilai penguatan yang diberikan oleh sistem penguat adalah 5 kali. Hasil pengukuran laju suhu menggunakan sistem akusisi berbasis ADC0804 dari alat pemanas adalah 0,390625 ${ }^{\circ} \mathrm{C} / \mathrm{s}$.

\section{DAFTAR PUSTAKA}

Anonim, N. Semikonduktor. LM35/LM35A/LM35C/LM35CA/LM35D Precision Centigrade Temperature Sensors, http://www.alldatasheet.com/datasheet-df/pdf/8866/NSC/LM35.html, diakses 10 Juli 2016

FRADEN, J., 2003, Handbook Of Modern Sensors Physics, Designs, And Applications, Prentice Hall, New Jersey

Handoyo, G, B., 2008, Perancangan Signal Conditioning Termokopel Tipe K Sebagai masukan ADC 0804, pp. 1-4.

Jefri, W, B, 2007, 12 Proyek Sistem Akuisisi Data:, PT. Elex Media Komputindo,

Nurhayati, 2012, Rancang Bangun Alat Pengontrol Suhu Berbasis Mikrokontroler Pada Pembuatan Bioetanol Berbahan Baku Kulit Pisang,"vol. JTE. Volume 01 Nomor 02, pp. 1-7

Sadiku,K, A, 2009, Fundamental of Electric Circuit, fourth edition ed., Raghothaman Srinivasam, McGraw-Hill Companies.

Santoso, B, S, 2013, Rancang Bangun Sistem Pengaturan Kecepatan Coolpad Menggunakan Sistem Kontrol Logika Fuzzy, http://repo.eepis-its.edu/265/1/7306040014_m.pdf. diakses 30 juli 2016

Shatomedia, Sensor Suhu LM35, http://shatomedia.com/, diakses 5 juli 2016 